\section{Comparison of inte- grated evoked EMG between the hypothenar and facial muscle groups following atracurium and vecuronium administration}

M.D. Sharpe MD, C.A. Moote MD, A.M. Lam MD, P.H. Manninen MD
In 17 healthy patients undergoing $\mathrm{O}_{2} \cdot \mathrm{N}_{2} \mathrm{O} \cdot$ isoflurane anaesthesia, following atracurium or vecuronium administration, we compared simultaneous integrated evoked electromyograms (IEEMGs) during spontaneous recovery of the adductor digiti minimi (ADM) and orbicularis oris (OOM) muscle groups in response to train-of-four (TOF) stimulation of the ulnar and facial nerves, respectively. In all patients, the onset of neuromuscular recovery occurred first in the OOM. The time required to recover to a $T_{4} / T_{1}=0.70 \pm 0.01$ (SD) was earlier in the OOM compared with the ADM muscles in both the atracurium (33.4 \pm 5 vs $46.5 \pm 8, P<0.005)$ and vecuronium $(46.5 \pm 12$ vs $60.3 \pm 20, P<0.005)$ groups. When the OOM attained a $T_{4} / T_{1}=0.70 \pm 0.01$, the simultaneous $T_{4} / T_{1}$ in the $A D M$ was $0.29 \pm 0.15(P<0.05)$ in the atracurium group and $0.41 \pm$ $0.16(P<0.01)$ in the vecuronium group. We conclude that $(I)$ the facial muscles (OOM) recover earlier than the hypothenar muscles ( $A D M$ ) and (2) an EMG $T_{4} / T_{1}=0.70$ in the facial muscles may not indicate adequate recovery of neuromuscular function.

\section{Key words}

MEASUREMENT TECHNIQUES: electromyography, neuromuscular blockade; NEUROMUSCULAR RELAXANTS: atracurium, vecuronium.

From the Department of Anaesthesia, University Hospital, University of Western Ontario, London, Ontario, Canada and Department of Anesthesiology, University of Washington, Scattle, Washington.

Address correspondence to: Dr. Michacl Sharpe, Department of Anaesthesia, University Hospital, 339 Windermere Road, London, Ontario, N6A 5A5.

Accepted for publication 22nd November, 1990
Nous avons compare les tracés électromyographiques intégrés de l'orbiculaire des paupières (ORB) et de l'adducteur du petit doigt $(A D D)$ évoqués simultanément par stimulation en train-de-quatre des nerfs facial et cubital; cela, pendant l'anesthésie avec $\mathrm{O}_{2}, \mathrm{~N}_{2} \mathrm{O}$ et isoflurane de 17 sujets sains après injection d'atracurium ou de vécuronium. Chez tous les patients, la récuperation de la fonction neuromusculaire survenait d'abord d l'ORB. Le temps requis pour retrouver un ratio de $T_{4} / T_{1} \pm 0,7 \pm 0,1$ (écart-type) était plus court pour l'ORB que pour l' $A D D$, a la fois avec l'atracurium $(33,4 \pm 5$ ws 46,5 \pm 8 $\min , P<0,005)$ et avec le vécuronium $(46,5 \pm 12$ vs $60,3 \pm 20$ $\min , P<0,005)$. Quand le $T_{4} / T_{1}$ de l'ORB atteignait $0,7 \pm 0,1$ celui de l' $A D D$ n'était que de $0,29 \pm 0,15(P<0,05)$ avec $l$ 'atracurium et que de $0,41 \pm 0,16$ avec le vécuronium $(P<$ $0,01)$. Après l' injection de myorelaxants, la fonction neuromusculaire des muscles du visage (ORB) récupère plus rapidement que celle des muscles de l'éminence hypothénar $(A D D)$ de plus, un ratio $T_{4} / T_{1}=0.7$ à l'EMG de la face n'est pas synonyme d'une récupération adéquate de la fonction neuromusculaire.

The importance of adequate reversal of muscle relaxants following a surgical procedure cannot be overemphasized. Accurate detection of any residual neuromuscular blockade predisposing the patient to respiratory muscle weakness is essential in order to prevent hypoventilation and/or upper airway obstruction. ${ }^{1.2}$ With the introduction of the peripheral nerve stimulator using train-of-four (TOF) and tetanic stimulation, the anaesthetist has a bedside monitor of neuromuscular function. ${ }^{3.4}$ Studies stimulating the ulnar nerve and measuring the mechanical response of the thenar muscles have correlated degrees of neuromuscular blockade with indices of respiratory function. ${ }^{5-8}$ Due to its accessibility and convenience, the facial nerve/muscle has also become a popular site for monitoring of neuromuscular blockade. Its efficacy, 
however, as an accurate monitor to assess the degree of residual neuromuscular blockade and therefore to predict postoperative respiratory muscle function has not been well defined. Our study was therefore designed to study the relationship between the integrated evoked electromyograms (IEEMGs) of the hypothenar and facial muscle groups during recovery from neuromuscular blockade. We wished to characterize the time course of recovery of the $T_{4} T_{1}$ ratio from TOF facial nerve stimulation in relationship to ulnar nerve stimulation, and in particular, determine whether TOF stimulation of the facial and ulnar nerves provided similar information regarding recovery of neuromuscular function.

\section{Methods}

With institutional human subjects review board approval, 17 healthy patients (ASA physical status I-II) with no known renal, hepatic or neuromuscular disease, aged 18-61 yr were studied. General anaesthesia was induced with thiopentone $\left(4-5 \mathrm{mg} \cdot \mathrm{kg}^{-1}\right)$, lidocaine $(1.0 \mathrm{mg} \cdot$ $\left.\mathrm{kg}^{-1}\right)$ and fentanyl $\left(3 \mu \mathrm{g} \cdot \mathrm{kg}^{-1}\right)$. Tracheal intubation was facilitated with succinylcholine $\left(0.5-0.75 \mathrm{mg} \cdot \mathrm{kg}^{-}{ }^{\mathrm{I}}\right)$. Maintenance anaesthesia consisted of oxygen/nitrous oxide $\left(\mathrm{FlO}_{2}\right.$ 0.30-0.40 to maintain $\mathrm{SaO}_{2} \geq 96 \%$ (Nelcor oximeter, Model N1000) and isoflurane (0.5-1.0\% inspired). Positive-pressure ventilation was used to maintain normocapnia (Nelcor Capnograph, Model N1000). The two muscle relaxants were studied sequentially; nine patients received vecuronium and eight patients received atracurium.

Simultaneous IEEMGs were recorded with surface electrodes from the OOM (facial) and ADM (hypothenar) using two Datex NMT 221 monitors (Puritan-Bennett) (Figure 1). This monitor automatically delivers a supramaximal stimulus, stores the control response in memory and displays the subsequent response to TOF stimulation both as the ratio of the first twitch to control $\left(\mathrm{T}_{\mathrm{l}} / \mathrm{T}_{\mathrm{c}}\right)$ and the ratio of the fourth twitch to first twitch $\left(T_{4} / T_{1}\right)$. During the study continual recordings were made of the response to TOF supramaximal stimuli delivered at a frequency of $2 \mathrm{~Hz}$ to the ulnar and facial nerves every $20 \mathrm{sec}$.

Before control IEEMGs were recorded, at least $30 \mathrm{~min}$ were allowed to elapse following succinylcholine administration to ensure full recovery of the EMG. Atracurium

TABLE 1 Anthropometric characteristics

\begin{tabular}{llllll}
\hline & \multicolumn{2}{l}{ Age $(y r)$} & & & \multicolumn{2}{l}{ Weight $(\mathrm{kg})$} & \\
\cline { 2 - 3 } \cline { 5 - 6 } Group & Mean $\pm S D$ & Range & & Mean $\pm S D$ & Range \\
\hline Atracurium $n=8$ & $34 \pm 13$ & $20-61$ & $72 \pm 14$ & $51-94$ \\
Vecuronium $n=9$ & $23 \pm 14$ & $18-51$ & $74 \pm 10$ & $51-82$ \\
\hline
\end{tabular}

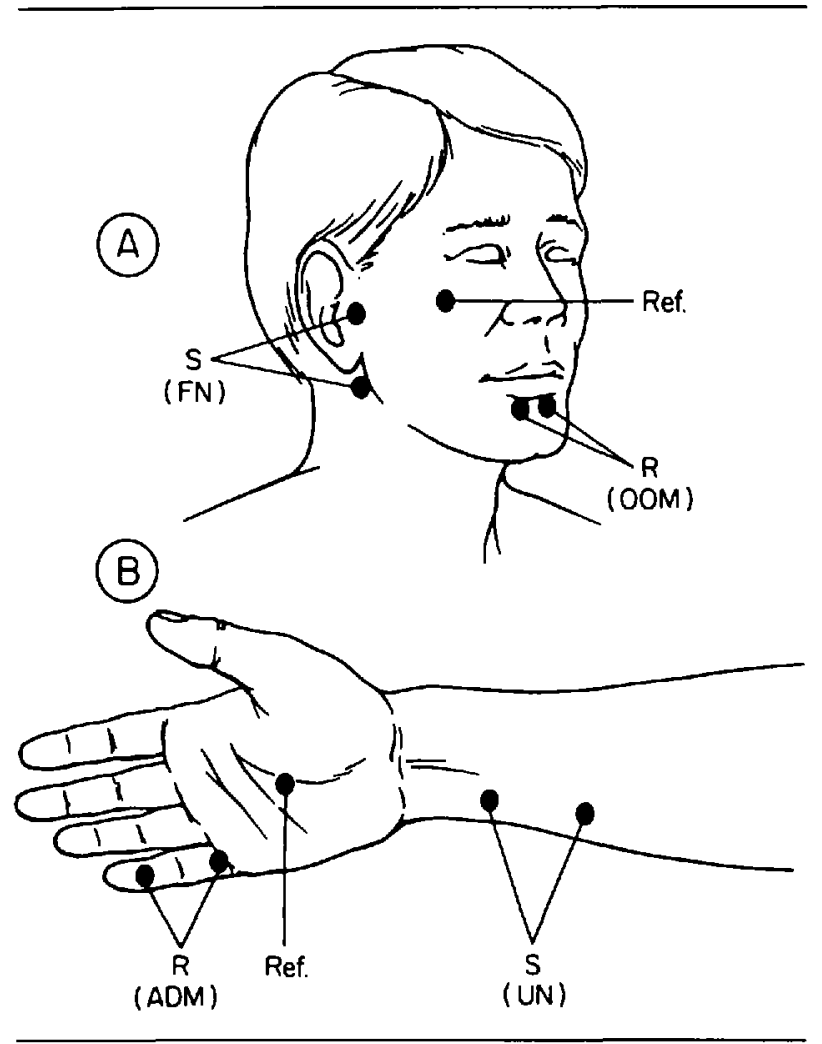

FIGURE 1 Schematic representation of placement of stimulating (S) and recording $(R)$ electrodes on the face and hand. UN = ulnar nerve, $F N=$ facial nerve, $A D M=$ adductor digiti minimi muscle, $\mathrm{OOM}=$ orbicularis oris muscle, Ref $=$ reference electrode

$\left(0.06-0.1 \mathrm{mg} \cdot \mathrm{kg}^{-1}\right)$ or vecuronium $(0.03-0.05 \mathrm{mg}$. $\mathrm{kg}^{-1}$ ) was administered (time 0 ) to abolish $\mathrm{T}_{4}$. The time at which maximal blockade was achieved in each muscle group as indicated by the $T_{4} / T_{1}$ digital display was recorded as mark 3 on the recording strip. Spontaneous recovery of neuromuscular function was monitored with continuous display of $T_{4} / T_{1}$ and $T_{1} / T_{c}$ ratios. When the $\mathrm{T}_{4} / \mathrm{T}_{1}$ ratio of the orbicularis oris muscle attained $0.70 \pm$ 0.01 , the simultaneous $T_{4} / T_{1}$ ratio of the hypothenar muscle was recorded. The recovery time (from time 0 to $\mathrm{T}_{4} / \mathrm{T}_{1}$ ratio of 0.70 ) was measured for each muscle group.

For statistical analysis, comparison of the recovery time for each muscle group was made using paired Student's $t$ test. Comparison between $T_{4} / T_{1}$ ratios of the hypothenar and orbicularis oris muscles when the latter was 0.70 was made using the Wilcoxin ranked-sum test. Results are expressed as mean \pm SD.

\section{Results}

The anthropometric characteristics of the two groups are shown in Table 1. The time of onset of neuromuscular blockade was similar in both muscle groups. Figure 2 is a representative study comparing the TOF response in the 


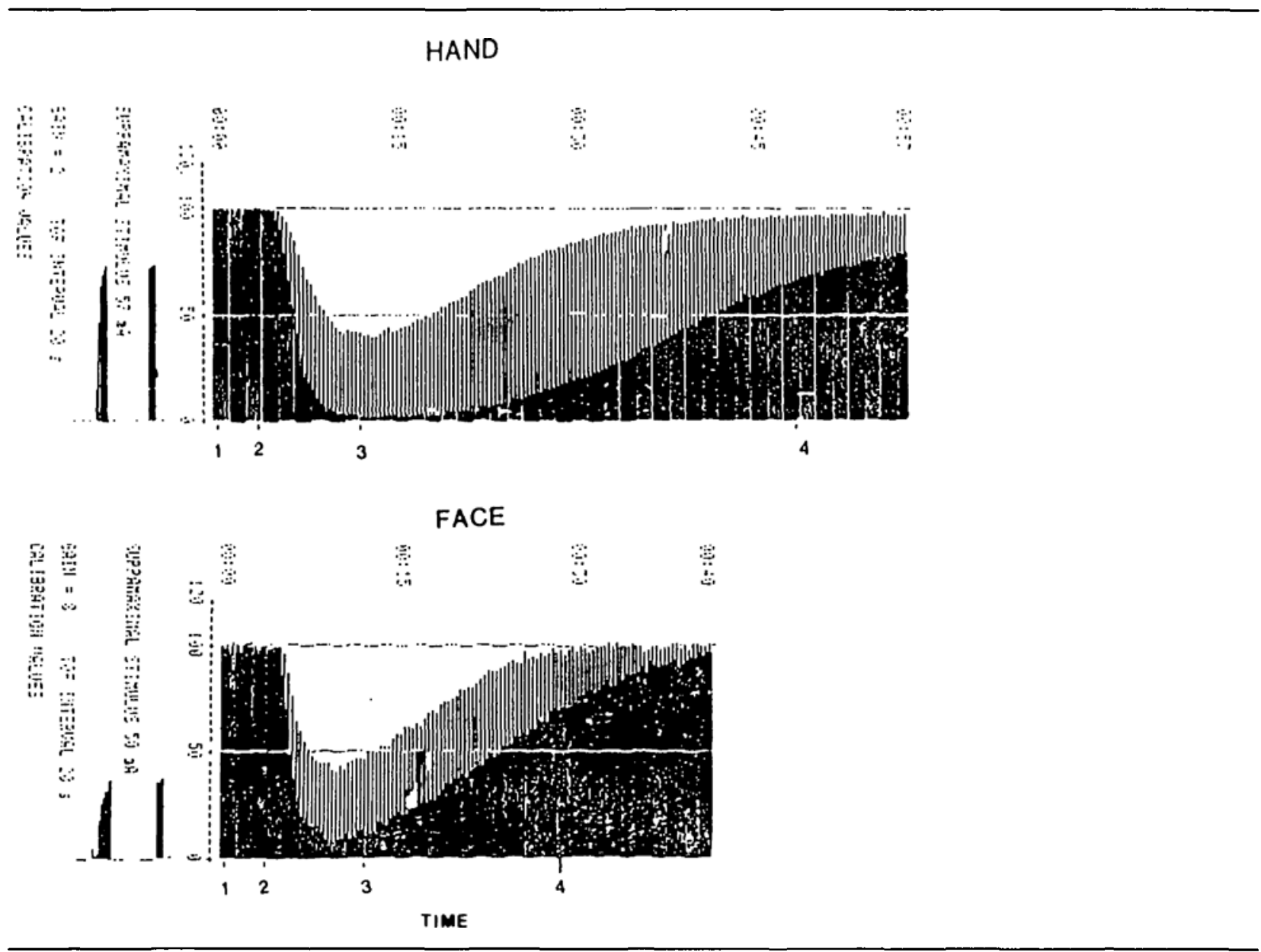

FIGURE 2 Simultaneous integrated evoked electromyograms of the adductor digiti minimi (hand) and orbicularis oris muscles (face) following vecuronium administration. $1=$ baseline IEEMG, $2=$ vecuronium injection, $3=$ point of maximum depression, $4=T_{4} / T_{1}=0.70 \pm 0.01$.

face and hand following vecuronium administration. Although this particular study suggests a more intense block in the facial muscle, we found no significant difference in intensity of block between the two muscle groups following atracurium or vecuronium administration. Note the earlier recovery of the facial EMG. The orbicularis oris muscle group was first to recover in all cases. The OOM recovered to $\mathrm{a}_{4} \mathrm{~T}_{1}$ ratio $=0.70 \pm 0.01$ approximately $13 \mathrm{~min}$ earlier than the ADM muscle in both the atracurium and vecuronium groups $(P<0.01)$ (Table II). When the OOM had recovered to a $\mathrm{T}_{4} \mathrm{~T}_{1}=$ $0.70 \pm 0.01$, the corresponding $T_{4} T_{1}$ of the ADM was only $0.29 \pm 0.15$ in the atracurium group $(P<0.05)$ and $0.41 \pm 0.16$ in the vecuronium group $(P<0.01)$ (Table III).

\section{Discussion}

During the conclusion of a general anaesthetic, it is essential to detect any residual neuromuscular blockade prior to extubation of the trachea in order to prevent respiratory insufficiency as a result of obstruction of the airway due to upper airway muscle weakness. Presently there is no direct bedside method to measure the integrity of the upper airway muscles involved in maintaining patency and providing protection of the upper airway as well as the muscles of respiration. Historically, several clinical tests such as head-lift, ${ }^{9}$ armlift ${ }^{10}$, tongue protrusion and intensity of hand-grip" ' have been utilized to assess the adequacy of neuromuscular function and as indirect tests of respiratory muscle function. However,

TABLE 11 Time (min) required to recover to a $\mathrm{T}_{4} / \mathrm{T}_{1}$ ratio $=$ $0.70 \pm 0.01$ for facial and hand muscle groups

\begin{tabular}{lll}
\hline & Atracurium $(\min )$ & Vecuronium $(\min )$ \\
\hline Orbicularis oris & $33.4 \pm 5^{*}$ & $46.5 \pm 12^{*}$ \\
Hypothenar & $46.5 \pm 8$ & $60.3 \pm 20$ \\
\hline
\end{tabular}

Mcan \pm SD

$* P<0.005$, between muscle groups 
these tests require an awake and cooperative patient and are not always accurate. ${ }^{2,12}$ Moreover, Pavlin et al. have recently demonstrated that despite having adequate spontaneous respiration during recovery from d-tubocurarine neuromuscular blockade, the patient may not be capable of maintaining a patent airway. ${ }^{13}$ It is, therefore, an established practice to monitor the neuromuscular junction using a peripheral nerve stimulator and observe the mechanical response (MMG) of the thenar muscles to TOF stimulation of the ulnar nerve. ${ }^{14}$ Studies have shown that MMG $T_{4} T_{1}$ ratio of 0.70 measured in the thenar muscle groups is consistent with adequate recovery of respiratory function. ${ }^{5-7}$

Our results indicate that the facial nerve/muscle preparation recovers faster than the ulnar nerve/hypothenar muscles; the OOM attained a $T_{4} T_{1}$ ratio of 0.70 by approximately $13 \mathrm{~min}$ earlier in both atracurium and vecuronium groups. At this time the $T_{4} T_{1}$ ratios of the ADM muscles were only 0.41 in the atracurium group and 0.29 in the vecuronium group. Our results are in agreement with previous studies ${ }^{15-17}$ which qualitatively indicated that the facial nerve recovered earlier than the hand muscles. Caffrey et al. ${ }^{16}$ had previously compared the orbicularis oculi with the adductor pollicis as a monitoring site for neuromuscular blockade, and although they studied the MMG (mechanical myogram) and we used the IEEMG, the results are remarkably similar with the hand muscles lagging behind the facial muscles by approximately 13 min during recovery. In contrast, Paloheimo et al. ${ }^{18}$ attempted to study the comparative IEEMG of orbicularis oculi and the hypothenar muscles and found the results to be too variable to be conclusive, although their results are consistent with an earlier recovery of the facial muscles. The variability in their study, an observation we had also made in earlier pilot studies, may be due to direct muscle stimulation. Such variability was not observed using the orbicularis oris as we had done in this study. Based on these findings, we conclude that adequate recovery of the EMG response to facial nerve stimulation is compatible with considerable residual neuromuscular blockade and therefore does not ensure adequate respiratory function. It should be mentioned that not all facial

TABLE III $T_{4} / T_{1}$ ratios of hypothenar muscle when orbicularis oris muscle $T_{4} / T_{1}=0.70 \pm 0.01$

\begin{tabular}{lll}
\hline & Acracurium & Vecuronium \\
\hline Orbicularis oris & $0.70 \pm 0.01$ & $0.70 \pm 0.01$ \\
Hypothenar & $0.29 \pm 0.15^{\dagger}$ & $0.41 \pm 0.16^{*}$ \\
\hline
\end{tabular}

Mean $\pm S D$.

$* P<0.05$, between muscle groups.

$\dagger P<0.01$, between muscle groups. muscles behave in the same manner, as it has been demonstrated that the masseter muscle is more sensitive to neuromuscular blockade than the adductor pollicis. ${ }^{19}$ Indeed, as a muscle partly responsible for maintenance of the airway, this sensitivity may account for the partial airway obstruction observed during recovery from neuromuscular blockade reported by Pavlin et al. ${ }^{13}$ However, clinically the masseter muscle is seldom used as a monitoring site for neuromuscular blockade.

As previous studies concluding that a $T_{4} T_{1}$ ratio of 0.70 is consistent with adequate recovery of respiratory function are mostly measured by $M M G,{ }^{4-6}$ our assumption that the information provided by the IEEMG is comparable to MMG needs to be addressed. Four separate studies comparing these two monitoring modalities, EMG vs MMG, have shown that the MMG consistently lags behind the EMG during recovery from a non-depolarizing neuromuscular blockade. ${ }^{20-23}$ However, in two of these studies, ${ }^{22.23}$ the magnitude of these differences was relatively small and considered clinically unimportant. Our own study on correlation between IEEMG and respiratory function also confirmed that a $\mathrm{T}_{4} \mathrm{~T}_{1}$ of $>0.7$ is consistent with adequate recovery. ${ }^{7}$ In contrast, Kopman $^{21}$ demonstrated a difference of 0.15 between EMG and $M M G T_{4} T_{1}$ ratios which was consistent throughout the study. A recent clinical study by Dupuis et al. confirmed that the EMG lags behind the MMG by approximately $20 \%$ which is compatible with Kopman's observations. ${ }^{24}$ This disparity between EMG and MMG measurement of neuromuscular blockade may be related to the type of anaesthetic administered. For example, the studies by Kopman ${ }^{21}$ and Caffrey et al. ${ }^{16}$ indicating a lag of the MMG utilized a halogenated agent to maintain anaesthesia whereas the studies by Harper ${ }^{22}$ and Weber ${ }^{23}$ indicating no significant disparity between the EMG and MMG, utilized a narcotic technique. Since the MMG is not only dependent upon neuromuscular transmission but also upon the contractility and loading of the muscle, the lag of the MMG may be explained by the effects of the halogenated agents upon these latter two factors. These considerations do not affect the validity of our study, since we did not use MMG, and the anaesthetic technique used would have little influence on EMG. However, they do lend further support to our contention that the OOM electromyography may not be a reliable indicator of the integrity of neuromuscular transmission as its recovery preceded ADM recovery in all cases. As well, observations made by Laycock et al. ${ }^{25}$ and Donati $e t a l .{ }^{26}$ that the diaphragm is more resistant to neuromuscular blockade than the thenar muscles suggest that this important respiratory muscle would also recover earlier than the thenar muscles. It is therefore probable that the recovery of OOM EMG may parallel that of the diaphragm and 
indicate at least the onset of recovery of respiratory function. Indeed, the relative time course of recovery of the diaphragm, orbicularis oculi (OOC) and adductor pollicus was recently studied by Donati $e t$ al. and the recovery potential of the diaphragm and OOC were shown to be quite similar. ${ }^{27}$ More importantly, however, the recovery of the adductor pollicus occurred later than that of the diaphragm or OOC which suggests adequate recovery of other important muscle groups, i.e., upper airway muscles involved in airway patency, has not yet occurred.

In summary, the facial nerve/muscle preparation is a convenient and accessible site of monitoring neuromuscular blockade, and the orbicularis oris may be a better alternative to orbicularis oculi for EMG recording. However, similar to orbicularis oculi, its earlier recovery probably reflects the time course of recovery of the diaphragm and underestimates the recovery of other important muscles of respiration necessary to maintain a patent airway. We conclude that recovery of facial nerve/muscle EMG may not represent adequate recovery of respiratory function and emphasize the need for further clinical evaluation of adequate muscle strength.

\section{References}

I Ali HH. A new device for monitoring force of thumb adduction. Br J Anacsth 1970; 142: 83-5.

2 Walts $L F$, Levin N, Dillon JB. Assessment of recovery from curare. JAMA 1970; 213: 1894-6.

3 Ali HH, Utting JE, Gray TC. Quantitative assessment of residual antidepolarizing block (Part I). Br J Anaesth 1971; 43: 473-6.

4 Ali HH, Wilson RS, Savarese JJ, Kitz RJ. The effect of tubocurarine on indirectly elicited train-of-four muscle response and respiratory measurements in humans. $\mathrm{Br} \mathrm{J}$ Anaesth 1975; 47: 570-3.

5 Brand JB, Cullen DJ, Wilson NE, Ali HH. Spontancous recovery from non depolarizing neuromuscular blockade: correlation between clinical and evoked responses. Anesth Analg 1977; 56: 55-8.

6 Ali $H H$, Kitz RJ. Evaluation of recovery from nondepolarizing neuromuscular block, using a digital neuromuscular transmission analyzer: preliminary report. Anesth Analg 1973; 52: 740-4.

7 Sharpe MD, Lam AM, Nicholas JF et al. Correlation between integrated evoked EMG and respiratory function following atracurium administration in unanaesthetized humans. Can J Anaesth 1990; 37: 307-12.

8 Lee CM. Train-of-4 quantitation of competitive neuromuscular block. Anesth Analg 1975; 54: 649-53.

9 Ali HH, Utting JE, Gray TC. Quantitative assessment of residual antidepolarizing block (Part II). Br J Anaesth 1971; 43: 478-85.
10 Bar ZG. The armlift test. Anaesthesia 1985; 40: 630-3.

11 Viby-Mogensen J. Clinical assessment of neuromuscular transmission. Br J Anacsth 1982; 54: 209-23.

12 Viby-Mogensen J, Jorgensen $B C$, Ording $H$. Residual curarization in the recovery room. Anesthesiology 1979; 50: 539-41.

13 Pavlin EG, Holle RH, Schoene RB. Recovery of airway protection compared with ventilation in humans after paralysis with curare. Anesthesiology 1989; 70: 381-5.

14 Day NS. Blake GJ, Standaert FG, Dretchen KL. Characterization of the train-of-four response in fast and slow muscle: effect of d-tubocurarine, pancuronium, and vecuronium. Anesthesiology 1983; 58: 414-7.

15 Ho LC, Crosby $G$, Sundaram $P$, Ronner SF, Ojemann $R G$. Ulnar train-of-four stimulation in predicting face movement during intracranial facial nerve stimulation. Anesth Analg 1989; 69: 242-4.

16 Caffrey RR, Warren ML, Becker KE. Neuromuscular blockade monitoring comparing the orbicularis oculi and adductor pollicis muscles. Anesthesiology 1986; 65: 95-7.

17 Stiffel P, Hameroff SR, Blitt CD, Cork RC. Variability in assessment of neuromuscular blockadc. Anesthesiology $1980 ; 52: 436-7$.

18 Paloheimo MPJ, Wilson RC, Edmonds $H L J r$, Lucas $L F$, Triantafillou AN. Comparison of neuromuscular blockade in upper facial and hypothenar muscles. J Clin Monit 1988; 4: 256-60.

19 Smith $C E$, Donati $F$, Bevan DR. Differential effects of pancuronium on masseter and adductor pollicis muscles in humans. Anesthesiology 1989; 71: 57-61.

20 Katz RL. Electromyographic and mechanical effects of suxamethonium and tubocurarine on twitch, tetanic and post-tetanic fade. Br J Anaesth 1973; 45: 849-59.

$21 K o p m a n A F$. The relationship of cvoked electromyographic and mechanical responses following atracurium in humans. Anesthesiology 1985; 63: 208-11.

22 Harper NJN, Bradshaw EG, Healy TEJ. Evoked clectromyograpic and mechanical responses of the adductor pollicis compared during the onset of neuromuscular blockade by atracurium or alcuronium, and during antagonism by neostigmine. $\mathrm{Br} \mathrm{J}$ Anaesth 1986; 58 : $1278-84$.

23 Weber S, Muravchick $S$. Electrical and mechanical train-of-four responses during depolarizing and non depolarizing neuromuscular blockade. Anesth Analg 1986; 65: 771-6.

24 Dupuis JY, Martin R, Tétrault JP. Clinical, clectrical and mechanical correlations during recovery from neuromuscular blockade with vecuronium. Can J Anaesth 1990; 37: $192-6$ 
25 Laycock JRD, Donati F, Smith CE. Bevan DR. Potency of atracurium and vecuronium at the diaphragm and the adductor pollicis muscle. Br J Anaesth 1988; 61: 286-91.

26 Donati F, Antzaka C, Bevan DR. Potency of pancuronium at the diaphragm and the adductor pollicis muscle in humans. Anesthesiology 1986; 65: 1-5.

27 Donati $F$, Meistelman C, Plaud B. Vecuronium neuromuscular blockade at the diaphragm, orbicularis oculi and adductor pollicis muscles. Can J Anaesth 1990; 37: S13. 